\title{
Iterative algorithm for approximating fixed points of multivalued quasinonexpansive mappings in Banach spaces
}

\author{
Ma'aruf Shehu Minjibir ${ }^{1,2^{*}}$ (D) and Chimezie Izuazu ${ }^{1}$
}

\section{"Correspondence:}

msminjibir.mth@buk.edu.ng

'African University of Science and

Technology, Abuja, Nigeria

${ }^{2}$ Bayero University, Kano, Nigeria

\begin{abstract}
Let $E$ be a strictly convex real Banach space and let $D \subseteq E$ be a nonempty closed convex subset of $E$. Let $T_{i}: D \rightarrow \mathcal{P}(D), i=1,2,3, \ldots$ be a countable family of quasinonexpansive multivalued maps that are continuous with respect to the Hausdorff metric, $\mathcal{P}(D)$ is the family of proximinal and bounded subsets of $D$. Supposing that the family has at least one common fixed point, we show that a Krasnoselskii-Mann-type sequence converges strongly to a common fixed point. Our result generalizes and complements some important results for single-valued and multivalued quasinonexpansive maps.
\end{abstract}

MSC: 47H09; 47H10; 47J25

Keywords: Stirctly convex Banach space; Multivalued quasinonexpansive maps; Hausdorff metric; Countable family of maps; Strong convergence

\section{Introduction}

Nonexpansive maps, that is, maps $T: C \rightarrow C, C$ subset of a normed space $X$, such that $\|T x-T y\| \leq\|x-y\|$ for all $x, y \in C$, constitute an important part of nonlinear operators that have been studied by numerous authors. Iterative processes for such maps turn out to be key tools in such areas as signal processing and image restoration (see, e.g., Byrne [1]). A proper superclass of the class of nonexpansive maps is that of quasinonexpansive maps, that is, maps $T: C \rightarrow C, C$ subset of a normed space $X$, such that $\|T x-y\| \leq\|x-y\|$ for all $x, y \in C$ with $T y=y$. This class was introduced by Diaz and Metcalfe [2] and Dotson [3] independently. For a nonexpansive map $T: C \rightarrow C$, Edelstein and O'brien [4] showed that $\left\|x_{n}-T x_{n}\right\| \rightarrow 0$ (uniformly), where $x_{n+1}=\lambda x_{n}+(1-\lambda) T x_{n}, n \geq 0, x_{0} \in C$ arbitrary and $C$ a convex and bounded nonempty subset of any normed linear space. Their result gave an affirmative answer to the question of whether strict convexity of $X$ can be dropped in showing that the sequence $\left\{x_{n}\right\}$ defined by the algorithm above converges strongly to a fixed point of $T$ (see Krasnoslskii [5], Edelstein [6] and Schaefer [7]). Concerning quasinonexpansive maps, Dotson [3] showed that the Mann sequence $x_{n+1}=\alpha_{n} x_{n}+\left(1-\alpha_{n}\right) T x_{n}$, $n \geq 0, x_{0} \in K$ satisfies $\left\|x_{n}-T x_{n}\right\| \rightarrow 0$ in a uniformly convex space. Unlike the case of non-

(c) The Author(s) 2022. This article is licensed under a Creative Commons Attribution 4.0 International License, which permits use, sharing, adaptation, distribution and reproduction in any medium or format, as long as you give appropriate credit to the original author(s) and the source, provide a link to the Creative Commons licence, and indicate if changes were made. The images or other third party material in this article are included in the article's Creative Commons licence, unless indicated otherwise in a credit line to the material. If material is not included in the article's Creative Commons licence and your intended use is not permitted by statutory regulation or exceeds the permitted use, you will need to obtain permission directly from the copyright holder. To view a copy of this licence, visit http://creativecommons.org/licenses/by/4.0/. 
expansive maps, this result does not hold in a general Banach space, as proved by Chidume [8].

Given a normed space $X$ and $\emptyset \neq C \subset X, \mathcal{C B}(C), \mathcal{K}(C), \mathcal{K C}(C)$ and $\mathcal{P}(C)$ denote the families of nonempty, closed and bounded, compact, compact and convex, and proximinal and bounded subsets of $C$, respectively, where a subset $D$ of $X$ is called proximinal if its distance from any point $x$ in $X$ is achieved, that is, $\operatorname{dist}(x, D):=\inf \{\|x-d\|: d \in D\}=\| x-$ $d_{0} \|$, for some $d_{0} \in D$. The Hausdorff metric on $\mathcal{C B}(C)$ is defined by

$$
d_{H}(A, B)=\max \left\{\sup _{a \in A} \operatorname{dist}(a, B), \sup _{b \in B} \operatorname{dist}(b, A)\right\}
$$

for all $A, B \in \mathcal{C B}(C)$. A map $T: C \rightarrow \mathcal{C B}(C)$ is said to be nonexpansive if

$$
d_{H}(T x, T y) \leq\|x-y\|, \quad \forall x, y \in C .
$$

We denote by $F(T)$ the set of all fixed points of $T$, that is, $F(T):=\{x \in C: x \in T x\}$. The mapping $T$ is called quasinonexpansive if

$$
d_{H}(T x, T p) \leq\|x-p\|, \quad \forall x \in C, p \in F(T) .
$$

For several decades, the fixed-point theory for multivalued maps has continued to receive the attention of many mathematicians (see, e.g., [9-18]). This may be connected to its numerous applications in so many areas, such as Game Theory, Market Economy, and Non-Smooth Differential Equations. Several works have been devoted to approximation of the fixed points of quasinonexpansive maps. Shahzad and Zegeye [19], using the Ishikawa iteration scheme, proved strong convergence theorems for quasinonexpansive multivalued maps in the setting of uniformly convex Banach space. Chidume and Minjibir [20] proved that a Krasnoselski sequence converges strongly to a fixed point of a multivalued quasinonexpansive map in uniformly convex spaces. They proved the following theorem.

Theorem CM ([20]) Let D be a nonempty closed convex subset of a uniformly convex real Banach space E. Suppose that $T: D \rightarrow \mathcal{C B}(D)$ is a multivalued quasinonexpansive mapping such that $T p=\{p\}$ for some $p \in F(T)$. Then, for any fixed $x_{0} \in D$ and $\lambda \in(0 ; 1)$, the sequence $\left\{x_{n}\right\}$ defined iteratively, by $x_{n+1}=(1-\lambda) x_{n}+\lambda y_{n} ; y_{n} \in T x_{n}, n=0,1,2, \ldots$ Then, $\lim _{n} \operatorname{dist}\left(x_{n}, T x_{n}\right)=0$.

Under additional mild compactness-type conditions, they obtained strong convergence of $\left\{x_{n}\right\}$ to a fixed point of the multivalued map.

Many authors devote time to studying methods for approximating common fixed points of the family of nonexpansive mapings and their generalizations, see, e.g., Uddin et al. [21]. The extension of the work of Chidume and Minjibir [20] to a finite family of quasinonexpansive mappings was given by Diop et al. [22]. They developed the algorithm:

$$
\left\{\begin{array}{l}
x_{0} \in D \\
x_{n+1}=\lambda_{0} x_{n}+\sum_{i=1}^{m} \lambda_{i} y_{n}, \quad y_{n} \in T_{i} x_{n}, n \geq 0 \\
\lambda_{0}, \lambda_{i} \in(0,1), \quad \sum_{i=0} \lambda_{i}=1
\end{array}\right.
$$


where $T_{i}: D \longrightarrow \mathcal{C B}(D), i=1,2,3, \ldots, m$ are a finite family of multivalued quasinonexpansive mappings such that $T_{i} p=\{p\}$ for every common fixed point and for all $i$. They proved that if $D$ is a nonempty closed convex subset of a uniformly convex real Banach space and the maps $T_{i}$ s have a common fixed point, then $\lim _{n \rightarrow \infty} \operatorname{dist}\left(x_{n}, T_{i} x_{n}\right)=0$ for each $i$. They further obtained strong convergence of $\left\{x_{n}\right\}$ to a common fixed point under additional mild conditions.

It is our purpose in this paper to develop a Krasnoselskii-Mann-type algorithm for approximating a common fixed point of a countable family of quasinonexpansive mappings in the setting of strictly convex Banach spaces and prove the strong convergence of the generated sequence to a common fixed point, given that such fixed point exists. The method of proof is akin to that of Dotson [3].

\section{Preliminaries}

In this section we state three lemmas that are used in the next section.

Lemma 2.1 ([3]) Let E be a strictly convex Banach space. If we let $x, y \in E$ such that $\|x\| \leq$ $\|y\|$ and $\|(1-\lambda) y+\lambda x\|=\|y\|$, for some $\lambda \in(0,1)$, then $y=x$.

Lemma 2.2 ([23]) If $K$ is a compact subset of a Banach space E, then the closed convex hull of $K, \overline{\mathrm{co}}(K)$ is compact.

Lemma 2.3 ([20]) If $x, y, z \in D$ such that $T y=\{z\}$, then

$$
\|u-z\| \leq d_{H}(T x, T y), \quad \forall u \in T x .
$$

\section{Main results}

We first prove the following lemmas that are key to the proof of our main theorem.

Lemma 3.1 Let $E$ be a strictly convex Banach space and let $\left\{x_{n}\right\}_{n} \subseteq E$.

(i) If $\left\{\lambda_{i}\right\}_{i=1}^{m} \subseteq(0,1)$ such that $\sum_{i=1}^{m} \lambda_{i}=1,\left\|x_{i}\right\| \leq\left\|x_{1}\right\|$, for all $i$ and $\left\|\sum_{i=1}^{m} \lambda_{i} x_{i}\right\|=\left\|x_{1}\right\|$, then $x_{i}=x_{1}$, for all $i$.

(ii) If $\left\{\lambda_{i}\right\}_{i} \subseteq(0,1)$ such that $\sum_{i=1}^{\infty} \lambda_{i}=1,\left\|x_{i}\right\| \leq\left\|x_{1}\right\|$, for all $i$ and $\left\|\sum_{i=1}^{\infty} \lambda_{i} x_{i}\right\|=\left\|x_{1}\right\|$, then $x_{i}=x_{1}$, for all $i$.

Proof

(i) We proceed by induction. For $m=2$ the assertion holds by Lemma 2.1. Suppose the assertion holds for some $n \geq 2$. Let $\left\{\lambda_{i}\right\}_{i=1}^{n+1} \subseteq(0,1)$ such that $\sum_{i=1}^{n+1} \lambda_{i}=1$, $\left\|x_{i}\right\| \leq\left\|x_{1}\right\|$, for all $i$ and $\left\|\sum_{i=1}^{n+1} \lambda_{i} x_{i}\right\|=\left\|x_{1}\right\|$. Set $W_{k}:=\sum_{i=1}^{k} \lambda_{i} x_{i}, k \geq 1$. We have

$$
\begin{aligned}
\left\|W_{n+1}\right\| & =\left\|W_{n-1}+\left(\lambda_{n}+\lambda_{n+1}\right)\left(\frac{\lambda_{n}}{\left(\lambda_{n}+\lambda_{n+1}\right)} x_{n}+\frac{\lambda_{n+1}}{\left(\lambda_{n}+\lambda_{n+1}\right)} x_{n+1}\right)\right\| \\
& =\left\|x_{1}\right\| .
\end{aligned}
$$

Since

$$
\left\|\frac{\lambda_{n}}{\left(\lambda_{n}+\lambda_{n+1}\right)} x_{n}+\frac{\lambda_{n+1}}{\left(\lambda_{n}+\lambda_{n+1}\right)} x_{n+1}\right\| \leq\left\|x_{1}\right\|
$$


by an inductive hypothesis we have

$$
x_{1}=x=\cdots=x_{n-1}=\frac{\lambda_{n}}{\left(\lambda_{n}+\lambda_{n+1}\right)} x_{n}+\frac{\lambda_{n+1}}{\left(\lambda_{n}+\lambda_{n+1}\right)} x_{n+1} .
$$

We now show $x_{n+1}=x_{n}$. If this is not the case, then $\frac{x_{n}}{\left\|x_{1}\right\|}, \frac{x_{n+1}}{\left\|x_{1}\right\|} \in B_{E}$ and $\frac{x_{n}}{\left\|x_{1}\right\|} \neq \frac{x_{n+1}}{\left\|x_{1}\right\|}$ (if $x_{1}=0$ the assertion follows immediately). By the strict convexity of $E$, we must have

$$
\left\|\frac{\lambda_{n}}{\left(\lambda_{n}+\lambda_{n+1}\right)}\left(\frac{x_{n}}{\left\|x_{1}\right\|}\right)+\frac{\lambda_{n+1}}{\left(\lambda_{n}+\lambda_{n+1}\right)}\left(\frac{x_{n+1}}{\left\|x_{1}\right\|}\right)\right\|<1
$$

This yields

$$
\left\|\frac{\lambda_{n}}{\left(\lambda_{n}+\lambda_{n+1}\right)} x_{n}+\frac{\lambda_{n+1}}{\left(\lambda_{n}+\lambda_{n+1}\right)} x_{n+1}\right\|<\left\|x_{1}\right\|
$$

contradicting (3.1). Therefore, $x_{n}=x_{n+1}$. It then follows from (3.1) that $x_{i}=x_{j}$, for all $i, j$.

(ii) We first note that the series $\sum_{i=1}^{\infty} \lambda_{i} x_{i} \in E$ by the hypotheses. Let $i_{0} \in \mathbb{N}$. We have

$$
\left\|\sum_{i=1}^{i_{0}} \lambda_{i} x_{i}+\left(1-\lambda^{*}\right) \sum_{i=i_{0}+1}^{\infty} \frac{\lambda_{i}}{\left(1-\lambda^{*}\right)} x_{i}\right\|=\left\|x_{1}\right\|,
$$

where $\lambda^{*}=\sum_{i=1}^{i_{0}} \lambda_{i}$. Noting that

$$
\left\|\sum_{i=i_{0}+1}^{\infty} \frac{\lambda_{i}}{\left(1-\lambda^{*}\right)} x_{i}\right\| \leq\left(\frac{1}{\left(1-\lambda^{*}\right)} \sum_{i=i_{0}+1}^{\infty} \lambda_{i}\right)\left\|x_{1}\right\|=\left\|x_{1}\right\|,
$$

we conclude by (i) that $x_{i_{0}}=x_{1}$. Since $i_{0} \in \mathbb{N}$ was arbitrarily chosen, it follows that $x_{i}=x_{1}$, for all $i$.

Lemma 3.2 Let $D$ be a nonempty, closed and convex subset of a normed space E. Let $T_{i}: D \longrightarrow \mathcal{C B}(D)$ be quasinonexpansive for all $i \in \mathbb{N}$. Let $\lambda_{i} \in(0,1)$, for all $i \in \mathbb{N} \cup\{0\}$ with $\sum_{i=0}^{\infty} \lambda_{i}=1$. Suppose $D$ is bounded or $\left\{T_{i}\right\}_{i}$ is uniformly bounded (that is, $\bigcup_{i=1}^{\infty} T_{i}(B)$ is bounded for each bounded subset $B$ of $D)$. For any $x_{0} \in D$, define the sequence $\left\{x_{n}\right\}_{n}$ iteratively by $x_{n+1}=\lambda_{0} x_{n}+\sum_{i=1}^{\infty} \lambda_{i} u_{i, n}$, where $u_{i, n} \in T_{i} x_{n}$, for all $n \geq 0$. Suppose $p \in \bigcap_{i=1}^{\infty} F\left(T_{i}\right)$ such that $T_{i} p=\{p\}$, for all $i \in \mathbb{N}$. Then,

(i) $\left\|x_{n+1}-p\right\| \leq\left\|x_{n}-p\right\|$, for all $n \geq 1$.

(ii) If $\left\{x_{n}\right\}_{n}$ clusters at $y$ and $z$, then $\|y-p\|=\|z-p\|$.

Proof We first note that the series $\sum_{i=1}^{\infty} \lambda_{i} u_{i, n}$ is absolutely convergent if $D$ is bounded or $\left\{T_{i}\right\}_{i}$ is uniformly bounded. Also, since $D$ is closed and convex, the infinite sum belongs to $D$ for each $n$. Thus, the iterative sequence is well defined. 
(i) By Lemma 2.3 and the quasinonexpansiveness of $T_{i} \mathrm{~s}$, we have

$$
\begin{aligned}
\left\|x_{n+1}-p\right\| & =\left\|\lambda_{0}\left(x_{n}-p\right)+\sum_{i=1}^{\infty} \lambda_{i}\left(u_{i, n}-p\right)\right\| \\
& \leq \lambda_{0}\left\|x_{n}-p\right\|+\sum_{i=1}^{\infty} \lambda_{i}\left\|\left(u_{i, n}-p\right)\right\| \\
& \leq \lambda_{0}\left\|x_{n}-p\right\|+\sum_{i=1}^{\infty} \lambda_{i} d_{H}\left(T_{i} x_{n}, T p\right) \\
& \leq \lambda_{0}\left\|x_{n}-p\right\|+\sum_{i=1}^{\infty} \lambda_{i}\left\|x_{n}-p\right\| \\
& =\left\|x_{n}-p\right\|, \quad \forall n \geq 1 .
\end{aligned}
$$

Hence, $\left\|x_{n+1}-p\right\| \leq\left\|x_{n}-p\right\|, \forall n \geq 1$.

(ii) Let $\left\{w_{n}\right\}_{n}$ and $\left\{v_{n}\right\}_{n}$ be two subsequences of $\left\{x_{n}\right\}_{n}$ such that $w_{n} \rightarrow y$ and $v_{n} \longrightarrow z$.

From (i), we have that $\lim _{n \rightarrow \infty}\left\|x_{n}-p\right\|$ exists. Therefore,

$$
\|y-p\| \leq\left\|y-w_{n}\right\|+\left\|w_{n}-p\right\|
$$

and letting $n$ go to infinity, we have

$$
\|y-p\| \leq \lim _{n \longrightarrow \infty}\left\|x_{n}-p\right\|
$$

Also,

$$
\left\|w_{n}-p\right\| \leq\left\|w_{n}-y\right\|+\|y-p\|
$$

Letting $n$ go to infinity, we have

$$
\lim _{n \rightarrow \infty}\left\|x_{n}-p\right\| \leq\|y-p\|
$$

It then follows that $\|y-p\|=\lim _{n \rightarrow \infty}\left\|x_{n}-p\right\|$. Similarly, we obtain $\|z-p\|=\lim _{n \rightarrow \infty}\left\|x_{n}-p\right\|$. Hence, $\|y-p\|=\|z-p\|$.

Remark 1 We note that Lemma 3.2 applies to the sequence generated by a finite family:

$$
x_{n+1}=\lambda_{0} x_{n}+\sum_{i=1}^{m} \lambda_{i} u_{i, n}, \quad u_{i, n} \in T_{i} x_{n}, n \geq 0,
$$

where $\lambda_{i} \in(0,1), i=1,2,3, \ldots, m$ and $\sum_{i=0}^{m} \lambda_{i}=1$. Indeed, Let $i \in \mathbb{N}$ and assume that $T_{i}=$ $T_{m}$, for all $i \geq m$; for each $n$, define the following

$$
\alpha_{i}:= \begin{cases}\lambda_{i}, & 0 \leqq i \leqq m-1 \\ \frac{\lambda_{m}}{2^{i-m+1}}, & i \geq m\end{cases}
$$




$$
u_{i, n}:= \begin{cases}u_{i, n}, & 1 \leqq i \leqq m-1 \\ u_{m, n}, & i \geq m\end{cases}
$$

Then,

$$
\begin{aligned}
x_{n+1} & =\lambda_{0} x_{n}+\sum_{i=1}^{m} \lambda_{i} u_{i, n} \\
& =\lambda_{0} x_{n}+\sum_{i=1}^{m-1} \lambda_{i} u_{i, n}+\left(\sum_{i=1}^{\infty} \frac{1}{2^{i}}\right) \lambda_{m} u_{m, n} \\
& =\lambda_{0} x_{n}+\sum_{i=1}^{m-1} \lambda_{i} u_{i, n}+\sum_{i=1}^{\infty} \frac{\lambda_{m}}{2^{i}} u_{m, n} \\
& =\lambda_{0} x_{n}+\sum_{i=1}^{m-1} \lambda_{i} u_{i, n}+\sum_{i=m}^{\infty} \frac{\lambda_{m}}{2^{i-m+1}} u_{m, n} \\
& =\alpha_{0} x_{n}+\sum_{i=1}^{m-1} \alpha_{i} u_{i}+\sum_{i=m}^{\infty} \alpha_{i} u_{m, n} \\
& =\alpha_{0} x_{n}+\sum_{i=1}^{\infty} \alpha_{i} u_{m, n} .
\end{aligned}
$$

\subsection{Convergence theorems for a finite family}

Theorem 3.3 Let E be a strictly convex real Banach space and D be a nonempty, closed and convex subset of E. Let $T_{i}: D \longrightarrow \mathcal{P}(D)$ be quasinonexpansive and continuous with respect to the Hausdorff metric, for all $i \in \mathbb{I}$ with $\bigcap_{i=1}^{m} F\left(T_{i}\right) \neq \emptyset$ and $T_{i} p=\{p\}$, for all $p \in \bigcap_{i=1}^{m} F\left(T_{i}\right)$. Suppose $T_{i}(D)$ is contained in a compact set $K$ for all $i \in \mathbb{I}$. For any $x_{0} \in D$ define a sequence $\left\{x_{n}\right\}_{n}$ iteratively, by

$$
x_{n+1}=\lambda_{0, n} x_{n}+\sum_{i=1}^{m} \lambda_{i, n} u_{i, n}, \quad u_{i, n} \in T_{i} x_{n}, n \geq 0
$$

where $\left\{\lambda_{i, n}\right\}_{n} \subseteq(0,1), i \in \mathbb{I} \cup\{0\}, \sum_{i=0}^{m} \lambda_{i, n}=1, n \geq 0$. If for each $i \in \mathbb{I} \cup\{0\},\left\{\lambda_{i, n}\right\}_{n}$ clusters at some point of $(0,1)$, then $\left\{x_{n}\right\}_{n}$ converges strongly to a common fixed point of $T_{i} s$.

Proof The fact that the finite union of compact sets is compact together with Lemma 2.2 make the set $\overline{\mathrm{co}}\left(K \cup\left\{x_{0}\right\}\right)$ compact. Since $\left\{\lambda_{i, n}\right\}_{n}$ clusters at some point of $(0,1)$, for each $i \in \mathbb{I} \cup\{0\}$, and $\left\{x_{n}\right\}_{n \geq 1} \subseteq \overline{\operatorname{co}}\left(K \cup\left\{x_{0}\right\}\right)$, we obtain $\left\{\lambda_{i, n_{k}}\right\}_{k} \subseteq\left\{\lambda_{i, n}\right\}_{n}$ and $\left\{x_{n_{k}}\right\}_{k} \subseteq\left\{x_{n}\right\}_{n \geq 1}$ such that $\left\{\lambda_{i, n_{k}}\right\}$ converges to $\lambda_{i}$ in $(0,1)$, for each $i$, and $x_{n_{k}} \longrightarrow x^{*} \in \overline{\mathrm{co}}\left(K \cup\left\{x_{0}\right\}\right) \subseteq D$. This implies $d_{H}\left(T_{i} x_{n_{k}}, T_{i} x^{*}\right) \longrightarrow 0$. Also, since the corresponding sequences $\left\{u_{i, n_{k}}\right\}_{k} \subseteq K$, it follows that there exists $\left\{u_{i, n_{k_{j}}}\right\}_{j} \subseteq\left\{u_{i, n_{k}}\right\}_{k}$ such that $u_{i, n_{k_{j}}} \longrightarrow u_{i}{ }^{*} \in D$ for each $i$. Let $w_{i}{ }^{*} \in$ $T_{i} x^{*}$ such that $\left\|w_{i}{ }^{*}-u_{i}{ }^{*}\right\|=\inf _{u_{i} \in T_{i} x^{*}}\left\|u_{i}-u_{i}{ }^{*}\right\|$ (such $w_{i}{ }^{*}$ exists, since $T_{i} x^{*}$ is proximinal for each $i$ ). Hence,

$$
\begin{aligned}
\left\|w_{i}^{*}-u_{i}^{*}\right\| & \leq \inf _{u_{i} \in T_{i} x^{*}}\left\|u_{i}-u_{i, n_{k_{j}}}\right\|+\left\|u_{i, n_{k_{j}}}-u_{i}^{*}\right\| \\
& \leq \sup _{v \in T_{i} x_{n_{k_{j}}}} \inf _{u_{i} \in T_{i} x^{*}}\left\|u_{i}-v\right\|+\left\|u_{i, n_{k_{j}}}-u_{i}^{*}\right\| \\
& \leq d_{H}\left(T_{i} x_{n_{k_{j}}}, T_{i} x^{*}\right)+\left\|u_{i, n_{k_{j}}}-u_{i}^{*}\right\|, \quad \forall j \geq 1 .
\end{aligned}
$$


Letting $j$ go to infinity, we have $\left\|w_{i}{ }^{*}-u_{i}{ }^{*}\right\|=0$. Hence, $u_{i}{ }^{*}=w_{i}{ }^{*} \in T_{i} x^{*}$. Therefore,

$$
x_{n_{k_{j}}+1}=\lambda_{0, n_{k_{j}}} x_{n_{k_{j}}}+\sum_{i=1}^{m} \lambda_{i, n_{k_{j}}} u_{i, n_{k_{j}}} \longrightarrow \lambda_{0} x^{*}+\sum_{i=1}^{m} \lambda_{i} u_{i}{ }^{*} .
$$

Thus, $\left\{x_{n}\right\}_{n}$ clusters at $x^{*}$ and $\lambda_{0} x^{*}+\sum_{i=1}^{m} \lambda_{i} u_{i}{ }^{*}$. By Lemma 3.2(ii) and Remark 1 , we have

$$
\left\|\lambda_{0}\left(x^{*}-p\right)+\sum_{i=1}^{m} \lambda_{i}\left(u_{i}^{*}-p\right)\right\|=\left\|x^{*}-p\right\| .
$$

Also, by Lemma 2.3 and the definition of a quasinonespansive multivalued map, we have that $\left\|u_{i}{ }^{*}-p\right\| \leq\left\|x^{*}-p\right\|$, for each $i \in \mathbb{I}$. Since $E$ is strictly convex, we have by Lemma 3.1(i) that $x^{*}-p=u_{i}{ }^{*}-p$, for all $i$. This implies $x^{*}=u_{i}{ }^{*} \in T_{i} x^{*}$, for all $i$. Thus, $x^{*} \in \bigcap_{i=1}^{m} F\left(T_{i}\right)$ and so $T_{i} x^{*}=\left\{x^{*}\right\}$, for all $i$. Using Lemma 3.2(i) we conclude that $x_{n} \longrightarrow x^{*}$. Hence, the sequence defined above converges strongly to a common fixed point of $T_{i} \mathrm{~s}$.

Corollary 3.4 Let E be a strictly convex real Banach space and D be a nonempty, closed and convex subset of $E$. Let $T_{i}: D \longrightarrow \mathcal{P}(D), i=1,2,3, \ldots, m$ be quasinonexpansive and continuous with respect to the Hausdorff metric such that $\bigcap_{i=1}^{m} F\left(T_{i}\right) \neq \emptyset$ and $T_{i} p=\{p\}$, for all $p \in \bigcap_{i=1}^{m} F\left(T_{i}\right)$. Suppose there is a compact set $K$ in $D$ containing $T_{i}(D)$ for all $i$. For any $x_{0} \in D$, define a sequence $\left\{x_{n}\right\}_{n}$ iteratively by

$$
x_{n+1}=\lambda_{0} x_{n}+\sum_{i=1}^{m} \lambda_{i} u_{i, n}, \quad u_{i, n} \in T_{i} x_{n}, n \geq 0,
$$

where for each $i, \lambda_{i} \in(0,1)$ and $\sum_{i=0}^{m} \lambda_{i}=1$. Then, $\left\{x_{n}\right\}_{n}$ converges strongly to an element of $\bigcap_{i=1}^{m} F\left(T_{i}\right)$.

Proof We take $\left\{\lambda_{i, n}\right\}_{n}$ to be the constant sequence $\left\{\lambda_{i}\right\}_{n}$ for each $i$. Then, $\left\{\lambda_{i, n}\right\}_{n}$ clusters at $\lambda_{i}$ for each $i$ and so Theorem 3.3 applies.

Corollary 3.5 ([5]) Let E be a uniformly convex normed space and D be a nonempty, closed and convex subset of $E$. Let $f: D \longrightarrow D$ be nonexpansive and $f(D) \subseteq K \subseteq D, K$ compact. For any $x_{0} \in D$, let a sequence $\left\{x_{n}\right\}_{n}$ be defined iteratively by

$$
x_{n+1}=\frac{1}{2} x_{n}+\frac{1}{2} f\left(x_{n}\right), \quad n \geq 0 .
$$

Then, $\left\{x_{n}\right\}_{n}$ converges strongly to a fixed point off .

Proof By the Schauder fixed-point theorem [7], we have that $F(f) \neq \emptyset$. Also, define $T$ : $D \longrightarrow \mathcal{P}(D)$ by $T x=\{f(x)\}$. Then, the proof follows from Corollary 3.4.

Corollary 3.6 ([3]) Let E be a strictly convex normed space and D be a nonempty, closed and convex subset of $E$. Let $f: D \longrightarrow D$ be continuous and quasinonexpansive and $f(D) \subseteq$ $K \subseteq D, K$ compact. For any $x_{0} \in D,\left\{t_{n}\right\}_{n} \subseteq(0,1)$ such that $\left\{t_{n}\right\}_{n}$ clusters at some $t \in(0,1)$ 
let a sequence $\left\{x_{n}\right\}_{n}$ be defined iteratively by

$$
x_{n+1}=\left(1-t_{n}\right) x_{n}+t_{n} f\left(x_{n}\right), \quad n \geq 0 .
$$

Then, $\left\{x_{n}\right\}_{n}$ converges strongly to a fixed point of $f$.

Proof By the Schauder fixed-point theorem [7], we have that $F(f) \neq \emptyset$. Also, define $T$ : $D \longrightarrow \mathcal{P}(D)$ by $T x=\{f(x)\}$. Then, the proof follows from Corollary 3.4.

\subsection{Convergence theorems for an infinite family}

Theorem 3.7 Let E be a strictly convex real Banach space and let D be a nonempty, closed and convex subset of $E$. Let $T_{i}: D \longrightarrow \mathcal{P}(D)$ be quasinonexpansive and continuous with respect to the Hausdorff metric, for all $i \in \mathbb{N}$ with $\bigcap_{i=1}^{\infty} F\left(T_{i}\right) \neq \emptyset$ and $T_{i} p=\{p\}$, for all $p \in$ $\bigcap_{i=1}^{\infty} F\left(T_{i}\right)$. Suppose there is a compact set $K$ in $D$ containing $T_{i}(D)$ for all $i \in \mathbb{N}$. For any $x_{0} \in D$ define a sequence $\left\{x_{n}\right\}_{n}$ iteratively, by

$$
x_{n+1}=\lambda_{0} x_{n}+\sum_{i=1}^{\infty} \lambda_{i} u_{i, n}, \quad u_{i, n} \in T_{i} x_{n}, n \geq 0,
$$

where $\left\|u_{i, n}-u_{i, j}\right\| \leq \operatorname{dist}\left(T_{i} x_{n}, u_{i, j}\right)$ for all $j \leq n, \lambda_{i} \in(0,1), i \in \mathbb{N} \cup\{0\}, \sum_{i=0}^{\infty} \lambda_{i}=1$. Then, $\left\{x_{n}\right\}_{n}$ converges strongly to a common fixed point of $T_{i}$ s.

Proof In the iterative formula, $u_{i, n}$ is well defined since $T_{i} x_{n}$ is proximal for every $i$. Also, the series in the formula is convergent since $\left(T_{i}(D)\right)_{i}$ is uniformly bounded and $\sum_{i=0}^{\infty} \lambda_{i}$ is convergent. Furthermore, since $D$ is closed and convex, the series belongs to $D$. Thus, the sequence $\left\{x_{n}\right\}_{n}$ is well defined and contained in $\overline{c o}\left(K \cup\left\{x_{0}\right\}\right)$. Moreover, by Lemma 2.2 $\overline{\mathrm{co}}\left(K \cup\left\{x_{0}\right\}\right)$ is compact. It follows that there exists $\left\{x_{n_{k}}\right\}_{k} \subseteq\left\{x_{n}\right\}_{n}$ such that $x_{n_{k}} \rightarrow x^{*} \in$ $\overline{\mathrm{co}}\left(K \cup\left\{x_{0}\right\}\right) \subseteq D$. This implies $d_{H}\left(T_{i} x_{n_{k}}, T_{i} x^{*}\right) \longrightarrow 0$ for every $i$. From the choice of $u_{i, n} \in$ $T_{i} x_{n}$ in the iterative algorithm, we have

$$
\left\|u_{i, n_{k}}-u_{i, n_{l}}\right\| \leq \max \left\{\operatorname{dist}\left(T_{i} x_{n_{k}}, u_{i, n_{l}}\right), \operatorname{dist}\left(T_{i} x_{n_{l}}, u_{i, n_{k}}\right)\right\} \leq d_{H}\left(T_{i} x_{n_{k}}, T_{i} x_{n_{l}}\right) \rightarrow 0
$$

as $k, l \rightarrow \infty$ for all $i$. Hence, $\left\{u_{i, n_{k}}\right\}$ has a limit $u_{i}^{*} \in D$. Let $w_{i}{ }^{*} \in T_{i} x^{*}$ such that $\left\|w_{i}{ }^{*}-u_{i}{ }^{*}\right\|=$ $\inf _{u_{i} \in T_{i} x^{*}}\left\|u_{i}-u_{i}^{*}\right\|\left(T_{i} x^{*}\right.$ is proximinal). Then,

$$
\begin{aligned}
\left\|w_{i}^{*}-u_{i}^{*}\right\| & \leq \inf _{u_{i} \in T_{i} x^{*}}\left\|u_{i}-u_{i, n_{k}}\right\|+\left\|u_{i, n_{k}}-u_{i}^{*}\right\| \\
& \leq \sup _{v \in T_{i} x_{n_{k}}} \inf _{i} \in T_{i} x^{*} \\
& \leq d_{H}\left(T_{i} x_{n_{k}}, T_{i} x^{*}\right)+\left\|u_{i, n_{k}}-u_{i}^{*}\right\|, \quad \forall j \geq 1 .
\end{aligned}
$$

Since $T_{i}$ is continuous, letting $k$ go to infinity we have $\left\|w_{i}{ }^{*}-u_{i}{ }^{*}\right\|=0$. Hence, $u_{i}{ }^{*}=w_{i}{ }^{*} \in$ $T_{i} x^{*}$. Therefore,

$$
x_{n_{k}+1}=\lambda_{0} x_{n_{k}}+\sum_{i=1}^{\infty} \lambda_{i} u_{i, n_{k}} \longrightarrow \lambda_{0} x^{*}+\sum_{i=1}^{\infty} \lambda_{i} u_{i}^{*} .
$$


Thus, $\left\{x_{n}\right\}_{n}$ clusters at $x^{*}$ and $\lambda_{0} x^{*}+\sum_{i=1}^{\infty} \lambda_{i} u_{i}{ }^{*}$. By Lemma 3.2(ii), we have that

$$
\left\|\lambda_{0}\left(x^{*}-p\right)+\sum_{i=1}^{\infty} \lambda_{i}\left(u_{i}^{*}-p\right)\right\|=\left\|x^{*}-p\right\| .
$$

Also, by Lemma 2.3 and the definition of a quasinonexpansive multivalued map, we have that $\left\|u_{i}{ }^{*}-p\right\| \leq\left\|x^{*}-p\right\|$, for each $i \in \mathbb{N}$. Thus, we have by Lemma 3.1(ii) that $x^{*}-p=u_{i}{ }^{*}-p$ for all $i$. This implies $x^{*}=u_{i}^{*} \in T_{i} x^{*}$ for all $i$. It follows that $x^{*} \in \bigcap_{i=1}^{\infty} F\left(T_{i}\right)$ and so $T_{i} x^{*}=$ $\left\{x^{*}\right\}$. Using Lemma 3.2(i) we conclude that $x_{n} \longrightarrow x^{*}$. Hence, $\left\{x_{n}\right\}$ converges strongly to an element of $\bigcap_{i=1}^{\infty} F\left(T_{i}\right)$.

\section{Numerical experiments}

The results of the numerical experiments carried out are presented in this section. All the codes and figures were written/generated using MATLAB R14a on a PC: Intel(R) Core(TM) i5-3427U CPU @ 1.80 GHz 2.30 GHz.

We consider the family $\left(T_{i}\right)$ of mappings defined by $T_{i}:[0, \boldsymbol{\alpha}] \subseteq X \rightarrow X, T_{i} x=\left[0, \frac{x}{i}\right]$, $i=1,2, \ldots$, where $\boldsymbol{\alpha}$ is a fixed vector in $X, X$ a strictly convex Banach space, and $[x, y]$ denotes the set $\{\alpha x+(1-\alpha) y: \alpha \in[0,1]\}$. This is a family of quasinonexpansive mappings having a common fixed point of 0 . We use three different sets of parameters $\left(\lambda_{i, n}^{(1)}\right),\left(\lambda_{i, n}^{(2)}\right)$ and $\left(\lambda_{i, n}^{(3)}\right)$, where

Table 1 Numerical experiment for the three sets of parameters: $\left(\lambda_{i, n}^{(1)}\right),\left(\lambda_{i, n}^{(2)}\right)$ and $\left(\lambda_{i, n}^{(3)}\right)$

\begin{tabular}{|c|c|c|c|c|c|c|c|c|c|c|c|}
\hline \multirow[t]{2}{*}{$S / N$} & \multirow[t]{2}{*}{ Dim. } & \multirow[t]{2}{*}{$x_{0}$} & \multicolumn{3}{|c|}{$\left(\lambda_{i, n}^{(1)}\right)$} & \multicolumn{3}{|c|}{$\left(\lambda_{i, n}^{(2)}\right)$} & \multicolumn{3}{|c|}{$\left(\lambda_{i, n}^{(3)}\right)$} \\
\hline & & & $N$ & $\left\|x_{N}\right\|$ & Time $(\mathrm{s})$ & $N$ & $\left\|x_{N}\right\|$ & Time (s) & $N$ & $\left\|x_{N}\right\|$ & Time $(\mathrm{s})$ \\
\hline 1 & 3 & ¡1 & 30 & $6.2 \mathrm{E}-09$ & $3.6 \mathrm{E}-04$ & 18 & 4.6E-09 & $2.2 \mathrm{E}-04$ & 9 & 1.5E-09 & $1.3 \mathrm{E}-04$ \\
\hline 2 & 10 & i2 & 28 & $7.9 \mathrm{E}-09$ & $3.1 \mathrm{E}-04$ & 18 & 4.6E-09 & 2.2E-04 & 9 & $1.5 \mathrm{E}-09$ & $1.3 \mathrm{E}-04$ \\
\hline 3 & 10 & i3 & 32 & $8.5 \mathrm{E}-09$ & $4.3 \mathrm{E}-04$ & 20 & $8.4 \mathrm{E}-09$ & 2.3E-04 & 10 & $1.2 \mathrm{E}-09$ & $1.6 \mathrm{E}-04$ \\
\hline 4 & 20 & i4 & 31 & 7.6E-09 & $5.2 \mathrm{E}-04$ & 20 & $3.8 \mathrm{E}-09$ & $1.5 \mathrm{E}-04$ & 10 & $5.6 \mathrm{E}-10$ & 1.0E-04 \\
\hline 5 & 30 & i5 & 30 & $9.1 \mathrm{E}-09$ & $4.2 \mathrm{E}-04$ & 19 & $6.8 \mathrm{E}-09$ & $1.3 \mathrm{E}-04$ & 9 & $6.5 \mathrm{E}-09$ & 8.6E-05 \\
\hline 6 & 15 & i6 & 28 & 6.6E-09 & $3.2 \mathrm{E}-04$ & 18 & $3.8 \mathrm{E}-09$ & $1.3 \mathrm{E}-04$ & 9 & $1.2 \mathrm{E}-09$ & $1.7 \mathrm{E}-04$ \\
\hline 7 & 40 & ¡7 & 30 & $5.3 \mathrm{E}-09$ & $3.5 \mathrm{E}-04$ & 19 & $3.9 \mathrm{E}-09$ & 1.2E-04 & 9 & $3.8 \mathrm{E}-09$ & $9.5 \mathrm{E}-05$ \\
\hline 8 & 50 & i8 & 28 & $6.5 \mathrm{E}-09$ & 6.7E-04 & 18 & 3.7E-09 & $2.2 \mathrm{E}-04$ & 9 & $1.2 \mathrm{E}-09$ & $1.2 \mathrm{E}-04$ \\
\hline 9 & 30 & i9 & 28 & 8.7E-09 & 4.5E-04 & 18 & $5.0 \mathrm{E}-09$ & 2.1E-04 & 9 & 1.7E-09 & $1.0 \mathrm{E}-04$ \\
\hline 10 & 10 & ¡10 & 28 & 7.1E-09 & $3.2 \mathrm{E}-04$ & 18 & 4.0E-09 & $1.3 \mathrm{E}-04$ & 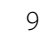 & 1.3E-09 & $1.0 \mathrm{E}-04$ \\
\hline 11 & 25 & i11 & 30 & 8.3E-09 & 4.1E-04 & 19 & $6.2 \mathrm{E}-09$ & 2.2E-04 & . & $6.0 \mathrm{E}-09$ & $1.3 \mathrm{E}-04$ \\
\hline 12 & 45 & ¡12 & 30 & 8.3E-09 & 3.4E-04 & 19 & $6.3 \mathrm{E}-09$ & 1.3E-04 & 9 & $6.0 \mathrm{E}-09$ & $8.6 \mathrm{E}-05$ \\
\hline 13 & 60 & ¡13 & 30 & $9.2 \mathrm{E}-09$ & $6.9 \mathrm{E}-04$ & 19 & $6.9 \mathrm{E}-09$ & 2.0E-04 & 9 & 6.7E-09 & 1.0E-04 \\
\hline 14 & 100 & ¡14 & 32 & $6.9 \mathrm{E}-09$ & 7.5E-04 & 20 & $6.8 \mathrm{E}-09$ & $1.3 \mathrm{E}-04$ & 10 & $1.1 \mathrm{E}-09$ & $1.5 \mathrm{E}-04$ \\
\hline 15 & 90 & ¡15 & 33 & 6.6E-09 & 3.7E-04 & 21 & 4.1E-09 & $1.3 \mathrm{E}-04$ & 10 & $1.8 \mathrm{E}-09$ & $1.1 \mathrm{E}-04$ \\
\hline 16 & 35 & ¡16 & 30 & $6.9 \mathrm{E}-09$ & $3.4 \mathrm{E}-04$ & 19 & $5.1 \mathrm{E}-09$ & $1.3 \mathrm{E}-04$ & 9 & $5.0 \mathrm{E}-09$ & $1.0 \mathrm{E}-04$ \\
\hline 17 & 120 & ¡17 & 33 & 9.7E-09 & $5.5 \mathrm{E}-04$ & 21 & $6.3 \mathrm{E}-09$ & $1.2 \mathrm{E}-04$ & 10 & 2.7E-09 & 1.6E-04 \\
\hline 18 & 65 & ¡18 & 31 & $5.4 \mathrm{E}-09$ & 3.6E-04 & 19 & $8.1 \mathrm{E}-09$ & $1.2 \mathrm{E}-04$ & 9 & 7.8E-09 & 1.3E-04 \\
\hline 19 & 10 & ¡19 & 33 & 8.0E-09 & 4.3E-04 & 21 & $5.2 \mathrm{E}-09$ & 1.6E-04 & 10 & 2.3E-09 & $1.9 \mathrm{E}-04$ \\
\hline 20 & 100 & $\mathrm{i} 20$ & 28 & $8.2 \mathrm{E}-09$ & $3.6 \mathrm{E}-04$ & 18 & 4.7E-09 & 2.3E-04 & 9 & 1.5E-09 & $1.1 \mathrm{E}-04$ \\
\hline 21 & 55 & i21 & 32 & 5.7E-09 & $3.8 \mathrm{E}-04$ & 20 & 5.7E-09 & $1.2 \mathrm{E}-04$ & 10 & 8.5E-09 & $1.5 \mathrm{E}-04$ \\
\hline 22 & 130 & $i 22$ & 32 & 6.6E-09 & $4.5 \mathrm{E}-04$ & 24 & 8.4E-09 & $2.8 \mathrm{E}-04$ & 11 & $1.9 \mathrm{E}-10$ & $1.6 \mathrm{E}-04$ \\
\hline 23 & 100 & i23 & 28 & 6.7E-09 & 4.0E-04 & 18 & $3.9 \mathrm{E}-09$ & $1.4 \mathrm{E}-04$ & 9 & $1.2 \mathrm{E}-09$ & $8.9 E-04$ \\
\hline 24 & 4 & $i 24$ & 31 & $6.2 \mathrm{E}-09$ & $5.4 \mathrm{E}-04$ & 19 & $9.2 \mathrm{E}-09$ & $1.4 \mathrm{E}-04$ & 9 & 8.9E-09 & $1.4 \mathrm{E}-04$ \\
\hline 25 & 80 & i25 & 30 & $6.4 \mathrm{E}-09$ & $3.5 \mathrm{E}-04$ & 19 & 4.8E-09 & 2.2E-04 & 9 & 4.6E-09 & $1.0 \mathrm{E}-04$ \\
\hline 26 & 200 & i26 & 32 & $6.1 \mathrm{E}-09$ & 7.4E-04 & 20 & $6.0 \mathrm{E}-09$ & 2.2E-04 & 10 & $5.9 \mathrm{E}-10$ & $1.8 \mathrm{E}-04$ \\
\hline 27 & 300 & $i 27$ & 31 & 7.3E-09 & 4.7E-04 & 20 & 3.6E-09 & 2.6E-04 & 10 & $5.5 \mathrm{E}-09$ & $1.9 \mathrm{E}-04$ \\
\hline 28 & 400 & $i 28$ & 34 & $7.8 \mathrm{E}-09$ & 4.3E-04 & 22 & 3.4E-09 & $1.8 \mathrm{E}-04$ & 10 & 4.5E-09 & $1.2 \mathrm{E}-04$ \\
\hline 29 & 500 & i29 & 33 & 5.6E-09 & 4.5E-04 & 21 & 3.7E-09 & 2.1E-04 & 10 & 1.6E-09 & $1.9 \mathrm{E}-04$ \\
\hline 30 & 1000 & i30 & 34 & 5.3E-09 & $4.9 \mathrm{E}-04$ & 21 & $6.8 \mathrm{E}-09$ & $3.4 \mathrm{E}-04$ & 10 & 3.0E-09 & $1.6 \mathrm{E}-04$ \\
\hline
\end{tabular}


Table 2 Initial points used in Table 1

\begin{tabular}{llll}
\hline$i 1$ & $i 2$ & $i 3$ & $i 4$ \\
$(1,2,3)$ & $\left(1, \frac{1}{2}, \frac{1}{3}, \ldots, \frac{1}{10}\right)$ & $(1,3,5, \ldots, 10)$ & $(1,1, \ldots, 1)$ \\
$i 5$ & $i 6$ & $i 7$ & $i 8$ \\
$(1,1,1, \ldots, 1)$ & $\left(1, \frac{1}{4}, \frac{1}{9}, \ldots, \frac{1}{225}\right)$ & $\left(\frac{1}{2}, \frac{1}{2}, \ldots, \frac{1}{2}\right)$ & $\left(1, \frac{1}{8}, \frac{1}{27}, \ldots, \frac{1}{125,000}\right)$ \\
$i 9$ & $i 10$ & $i 11$ & $i 12$ \\
$\left(\frac{1}{4}, \frac{1}{4}, \ldots, \frac{1}{4}\right)$ & $\left(1, \frac{1}{3}, \ldots, \frac{1}{19}\right)$ & $(1,1, \ldots, 1)$ & $\left(\frac{3}{4}, \frac{3}{4}, \ldots, \frac{3}{4}\right)$ \\
$i 13$ & $i 14$ & $i 15$ & $i 16$ \\
$\left(\frac{5}{7}, \frac{5}{7}, \ldots, \frac{5}{7}\right)$ & $\left(\frac{8}{5}, \frac{8}{5}, \ldots, \frac{8}{5}\right)$ & $(3,3,3, \ldots, 3)$ & $\left(\frac{7}{10}, \frac{7}{10}, \ldots, \frac{7}{10}\right)$ \\
$i 17$ & $i 18$ & $i 19$ & $i 20$ \\
$(4,4,4, \ldots, 4)$ & $\left(\frac{4}{5}, \frac{4}{5}, \ldots, \frac{4}{5}\right)$ & $(1,3,5, \ldots, 19)$ & $\left(1, \frac{1}{2}, \frac{1}{3}, \ldots, \frac{1}{100}\right)$ \\
$i 21$ & $i 22$ & $i 23$ & $i 24$ \\
$\left(\frac{9}{5}, \frac{9}{5}, \ldots, \frac{9}{5}\right)$ & $(1,4,7, \ldots, 301)$, & $(1,2.5,4, \ldots, 195)$ & $(2,3,4,5)$ \\
$i 25$ & $i 26$ & $i 27$ & $i 28$ \\
$\left(\frac{3}{7}, \frac{3}{7}, \ldots, \frac{3}{7}\right)$ & $(1,1,1, \ldots, 1)$ & $\left(\frac{1}{2}, \frac{1}{2}, \ldots, \frac{1}{2}\right)$ & $\left(\frac{7}{2}, \frac{7}{2}, \ldots, \frac{7}{2}\right)$ \\
$i 29$ & $i 30$ & & \\
$\left(\frac{8}{7}, \frac{8}{7}, \ldots, \frac{8}{7}\right)$ & $\left(\frac{3}{2}, \frac{3}{2}, \ldots, \frac{3}{2}\right)$ & & \\
\hline
\end{tabular}

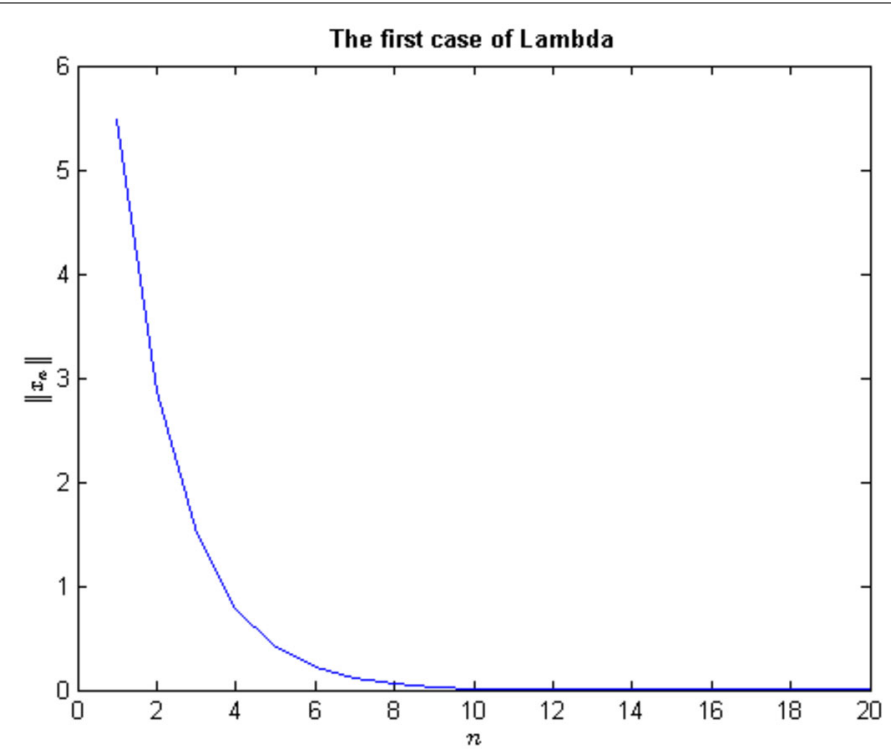

Figure 1 Graph corresponding to $\left(\lambda_{i, n}^{(1)}\right)$

- $\lambda_{i, n}^{(1)}:=\frac{1}{M+1}$, for all $i$, for all $n$,

- $\lambda_{0, n}^{(2)}:=\frac{1}{3}, \lambda_{i, n}^{(2)}=\frac{2}{3 M}, i=1,2, \ldots, M$, for all $n$, and

- $\lambda_{0, n}^{(3)}:=\frac{1}{3 n}$, and $\lambda_{i, n}^{(3)}=\frac{3 n-1}{3 n M}, i=1,2, \ldots, M$,

with $M$ being the number of maps.

All the three sets of parameters above verify the requirements of our theorems: $\left(\lambda_{i, n}^{(j)}\right) \subseteq$ $(0,1), j=1,2,3, \sum_{i=0}^{M} \lambda_{i, n}^{(j)}=1$ and $\lambda_{i, n}^{(j)} \rightarrow \lambda_{j}^{*} \in(0,1), j=1,2,3$. We note here that while our algorithm (3.7) involves an infinite sum, for the purpose of implementation on a computer, one has to use one finite term at a time. In Table 1, we report the outcome of the numerical implementation of our algorithm for the given maps $T_{i}$ defined above and for $X=\mathbb{R}^{n}$. In the table, we use a tolerance of $\epsilon=10^{-8}, S / N$ denotes the serial number, Dim. denotes 


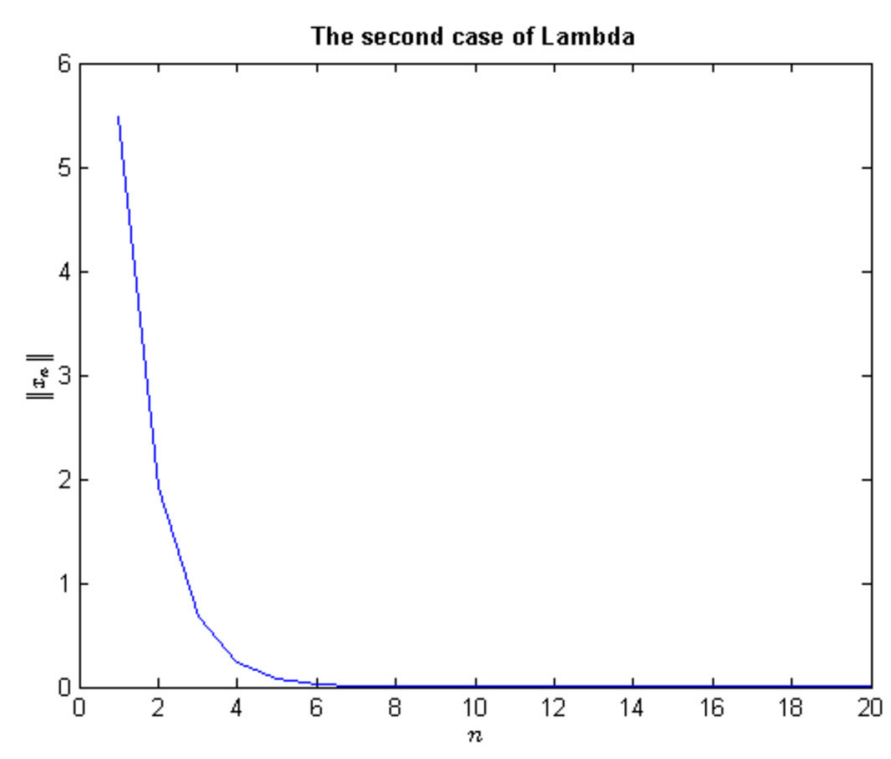

Figure 2 Graph corresponding to $\left(\lambda_{i, n}^{(2)}\right)$

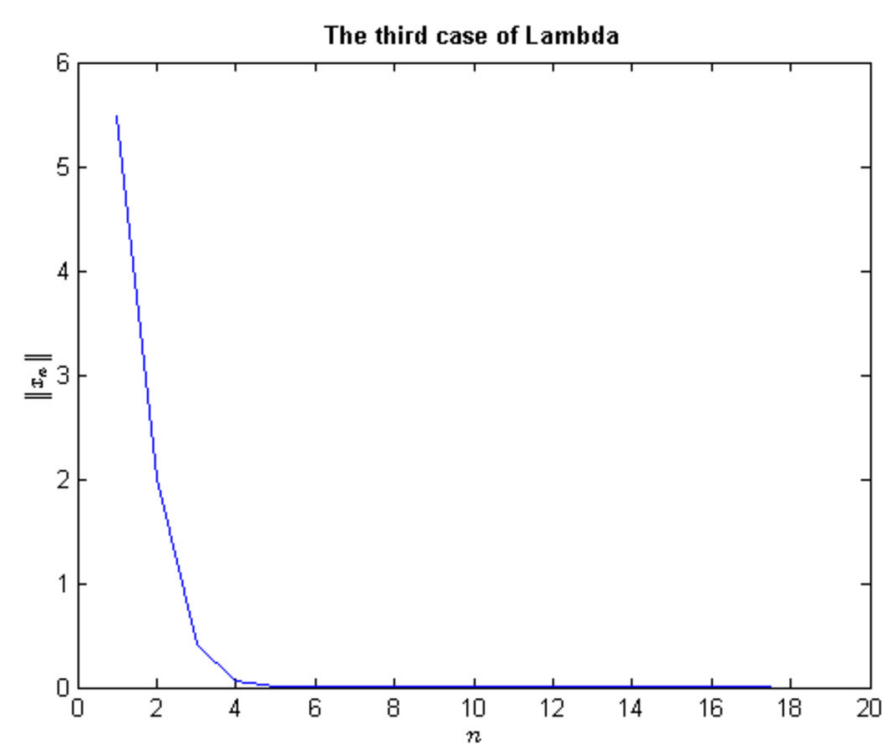

Figure 3 Graph corresponding to $\left(\lambda_{i, n}^{(3)}\right)$

dimension (i.e., the $n$ for which $X=\mathbb{R}^{n}$ ), $x_{0}$ refers to the initial term, which is given in Table 2, $N$ denotes the smallest $n$ such that $\left\|x_{n}\right\|<\epsilon$ and Time represents the CPU time in seconds.

It is clear from Table 1 that the convergence is faster, with regard to the number of iterations, for the case of $\left(\lambda_{i, n}^{(3)}\right)$ in which the values of $\lambda$ change with $n$. Following the case of $\left(\lambda_{i, n}^{(3)}\right)$ is the case of $\left(\lambda_{i, n}^{(2)}\right)$, while the case of $\left(\lambda_{i, n}^{(1)}\right)$ has the highest number of iterations. With respect to CPU time, there is not much difference between the case of $\left(\lambda_{i, n}^{(2)}\right)$ and that of $\left(\lambda_{i, n}^{(3)}\right)$, both of which have a lower CPU time than the case of $\left(\lambda_{i, n}^{(1)}\right)$. 
Figures 1-3 represent the graphs depicting the convergence of our algorithm for the three sets of parameters: $\left(\lambda_{i, n}^{(1)}\right),\left(\lambda_{i, n}^{(2)}\right)$ and $\left(\lambda_{i, n}^{(3)}\right)$ (given above), respectively.

\section{Acknowledgements}

The second author wishes to thank his institution for the support given to him as a student. The first author also wishes to thank both institutions for various forms of support given to them.

\section{Funding}

This work is supported partially by AfDB Research Grant Funds to AUST.

\section{Availability of data and materials}

Not applicable.

\section{Declarations}

\section{Competing interests}

The authors declare that they have no competing interests.

\section{Authors' contributions}

Both authors contributed equally in both carrying out the work and in writing the article. MSM and Cl studied the problem, proposed the algorithm, gave the convergence proof and the numerical illustrations. Both authors read and approved the final manuscript.

\section{Publisher's Note}

Springer Nature remains neutral with regard to jurisdictional claims in published maps and institutional affiliations.

Received: 15 February 2021 Accepted: 21 February 2022 Published online: 07 March 2022

\section{References}

1. Byrne, C.: A unified treatment of some iterative algorithms in signal processing and image restoration. Inverse Probl. 20, 103-120 (2004)

2. Diaz, J.B., Metcalf, F.T.: On the structure of the set of subsequential limit points of successive approximations. Bull. Am. Math. Soc. 73, 516-519(1967)

3. Dotson, W.G. Jr.: On the Mann iterative process. Trans. Am. Math. Soc. 149, 65-73 (1970)

4. Edelstein, M., O'brien, R.C.: Nonexpansive mappings, asypmtotic regularity and succesive approximations. J. Lond. Math. Soc. 17(2), 547-554 (1978)

5. Krasnosel'skii, M.A.: Two observations about the method of successive approximations. Usp. Mat. Nauk 10, 123-127 (1955)

6. Edelstein, M.: A remark on a theorem of Krasnoselskii. Am. Math. Mon. 13, 507-510 (1966)

7. Schaefer, H.: Über die Methode sukzessiver Approximationen. Jahresber. Dtsch. Math.-Ver. 59, 131-140 (1957) (German)

8. Chidume, C.E.: Quasi-nonexpansive mappings and uniform asymptotic regularity. Kobe J. Math. 3(1), $29-35$ (1986)

9. Nadler, S.B. Jr.: Multivalued contraction mappings. Pac. J. Math. 30, 475-488 (1969)

10. Lim, T.C.: A fixed point theorem for multivalued nonexpansive mappings in a uniformly convex Banach space. Bull. Am. Math. Soc. 80, 1123-1126 (1974)

11. Downing, D., Kirk, W.A.: Fixed point theorems for set-valued mappings in metric and Banach spaces. Math. Jpn. 22(1), 99-112 (1977)

12. Xu, H.-K.: Multivalued nonexpansive mappings in Banach spaces. Nonlinear Anal. 43, 693-706 (2001)

13. Abkar, A., Eslamian, M.: Convergence theorems for a finite family of generalized nonexpansive multi-valued mappings in cat(0) spaces. Nonlinear Anal. 75(4), 1895-1903 (2012)

14. Cardinali, T., Rubbioni, P.: Multivalued fixed point theorems in terms of weak topology and measure of weak noncompactness. J. Math. Anal. Appl. 405(2), 409-415 (2013)

15. Dinevari, T., Frigon, M.: Fixed point results for multivalued contractions on a metric space with a graph. J. Math. Anal. Appl. 405, 507-517 (2013)

16. Chidume, C.E., Chidume, C.O., Djitté, N., Minjibir, M.S.: Iterative algorithm for fixed points of multi-valued pseudo-contractive mappings in Banach spaces. J. Nonlinear Convex Anal. 15(2), 257-267 (2014)

17. Precup, R., Rodríguez-López, J.: Fixed point index theory for decomposable multivalued maps and applications to discontinuous $\phi$-Laplacian problems. Nonlinear Anal. 199, 111958 (2020)

18. Chidume, C.E., Chidume, C.O., Djitté, N., Minjibir, M.S.: Convergence theorems for fixed points of multivalued strictly pseudocontractive mappings in Hilbert spaces. Abstr. Appl. Anal. 2013, Article ID 629468 (2013)

19. Shazad, N., Zegeye, H.: On Mann and Ishikawa iteration schemes for multi-valued maps in Banach spaces. Nonlinear Anal. 71, 838-844 (2009)

20. Chidume, C.E., Minjibir, M.S.: Krasnoselskii algorithm for fixed points of multi-valued quasi-nonexpansive mappings in certain Banach spaces. Fixed Point Theory 17(2), 301-312 (2016)

21. Uddin, I., Ali, J., Nieto, J.J.: An iteration scheme for a family of multivalued mappings in CAT(0) spaces with an application to image recovery. Rev. R. Acad. Cienc. Exactas Fís. Nat., Ser. A Mat. 112, 373-384 (2018)

22. Diop, C., Sene, M., Djitté, N.: Iterative algorithms for a finite family of multivalued quasi-nonexpansive mappings. Adv. Numer. Anal. 2014, Article ID 181049 (2014)

23. Mazur, S.: Über die kleinste konvexe menge, die eine gegebene kompakte menge enthält. Stud. Math. 2, 7-9 (1930) 